\title{
PEMODELAN PENYEBARAN BATUAN POTENSIAL PEMBENTUK ASAM PADA KAWASAN PENAMBANGAN BATUBARA TAMBANG TERBUKA DI MUARA LAWA, KABUPATEN KUTAI BARAT, KALIMANTAN TIMUR \\ (Modeling Distribution of Rock Potential Acid Forming in Open Pit Coal Mining Areas in Muaralawa, West Kutai, East Kalimantan)
}

\author{
Shalaho Dina Devy ${ }^{1,2 *}$, Heru Hendrayana ${ }^{1}$, Dony Prakasa Eka Putra ${ }^{1}$ dan Eko Sugiharto ${ }^{3}$ \\ ${ }^{1}$ Jurusan Teknik Geologi, Fakultas Teknik, Universitas Gadjah Mada, \\ Jl. Grafika no. 2, Yogyakarta 55281. \\ ${ }^{2}$ Jurusan Teknik Pertambangan, Fakultas Teknik, Universitas Mulawarman, \\ Jl. Gn Kelua no. 1, Samarinda 75123. \\ ${ }^{3}$ Pusat Studi Lingkungan Hidup, Universitas Gadjah Mada, Sekip Utara, Yogyakarta 55281. \\ *Penulis korespondensi. Tel: 08125848054. Email: azvy_05@yahoo.co.id.
}

Diterima: 15 September 2015

Disetujui: 11 November 2015

\begin{abstract}
Abstrak
Dampak penambangan batubara tambang terbuka adalah munculnya Air Asam Tambang (AAT) di sekitar lingkungan penambangan yang mempengaruhi kualitas air tambang, biota air, kualitas air dan tanah. Oleh karena itu, informasi awal untuk mengantisipasi dampak tersebut, yaitu identifikasi batuan yang berpotensi asam dan memodelkan penyebarannya. Kajian geologi dan mineralogi batuan berperan dalam mengetahui penyebaran batuan Potential Acid Forming (PAF) dan Non Acid Forming (NAF). Kawasan tambang yang digunakan sebagai model penelitian berada di Kecamatan Muara Lawa, Kabupaten Kutai Barat, Kalimantan Timur. Hasil dari penelitian mengindikasikan, bahwa dominasi PAF berada di lapisan batu lempung kemudian diikuti batu lanau dan batu pasir dengan penyebaran mengikuti struktur sinklin yang terbatas di lapisan bawah (floor) dan lapisan antara (inter burden) pada batubara. Sementara itu, batuan NAF menyebar menempati daerah selain batuan PAF.
\end{abstract}

Kata kunci: air asam tambang, batubara, dampak lingkungan, sinklin, tambang terbuka.

\begin{abstract}
The impact of open pit coal mining is the emergence of Acid Mine Water (AMD) around the mining environment that affect the quality of the mine water, aquatic biota, water and soil quality. Therefore, early information to anticipate these impacts is the identification potential acid rock and distribution model as a guide for the mining plan. Geological and geochemical study of rocks is important in knowing the distribution of rock Potential Acid Formning (PAF) and Non Acid Forming (NAF). Mining area which is used as a research model was in Muara Lawa, West Kutai regency, East Kalimantan province. The results of the study indicate, that the dominance of PAF are in layers followed by siltstone, claystone and sandstone with the distribution of rock following the syncline structure in the bottom (floor) layer and in the inter-burden layer on coal. Meanwhile, rock NAF spread in areas other than rock PAF.
\end{abstract}

Keywords: acid mine water, coal, enviromentally impact, open pit mining, syncline.

\section{PENDAHULUAN}

Muara Lawa terdiri dari tiga formasi, yaitu Formasi Pamaluan, Pulaubalang, dan Balikpapan. Ketiga formasi ini membentuk struktur Sinklin Lampanan yang membentang dari timur laut menuju ke barat daya (Supriatna dkk, 1995). Cadangan batubara yang melimpah dari ketiga formasi tersebut mengakibatkan banyak perusahan yang melakukan aktivitas penambangan batubara dengan menggunakan metode tambang terbuka (Quamruzzaman dkk., 2014). Salah satu dampak dari penambangan batubara tambang terbuka adalah terbentuknya Air Asam Tambang (AAT) (Jamal dkk., 2015).
AAT merupakan air asam yang timbul akibat aktivitas penambangan yang berupa air lindian (leachate), rembesan (seapage), atau aliran (drainage). AAT adalah air yang bersifat asam mempunyai tingkat keasaman tinggi ditandai dengan nilai $\mathrm{pH}<5$ akibat dari reaksi oksidasi mineral sulfida, seperti pirit $\left(\mathrm{FeS}_{2}\right)$, yang terpapar di udara dengan kehadiran air (Sigh., 2006; Sand dkk., 2007).

Kegiatan yang bermanfaat untuk mengantisipasi oksidasi mineral sulfida dalam batuan dengan mengidentifikasi keberadaan mineralogi batuan potensial pembentuk asam (Potential Acid Forming, PAF) dan tidak potensial pembentuk asam (Non Acid Forming, NAF) (Johnson., dan Hallberg., 2006; Nugraha, dkk., 
2009; Zulkarnain dan Abdiyanto 2012). Perbedaan penelitian ini dengan penelitian sebelumnya yaitu dilakukannya pemodelan sebaran batuan PAF secara vertikal dan horisontal yang dikaitkan dengan jenis batuan.

\section{METODE PENELITIAN}

\section{Waktu dan Lokasi}

Penelitian dilakukan pada tanggal 1 April 2013 hingga 25 Mei 2013. Lokasi penelitian di operasi penambangan Blok Selatan PT. Trubaindo Coal Mining, di Muara Lawa, Kabupaten Kutai Barat. Metode yang diterapkan menggunakan uji statik dengan metode NAPP. Sampel berupa data log bor hasil pemboran full coring dari 17 lubang bor (Gambar 1).

\section{Prosedur \\ Metode NAPP}

Uji statik metode NAPP adalah metode untuk mengetahui pembentukan AAT melalui identifikasi dari karakteristik batuan yang mengandung mineral sulfida yang menitikberatkan pada analisis potensi keasaman tanah/batuan daerah tambang, yaitu berupa berat $\mathrm{kg} \mathrm{H}_{2} \mathrm{SO}_{4}$ tiap ton (Ian dkk. 2007). Parameter acuan untuk mengetahui potensi PAF atau NAF pada metode NAPP berdasarkan pada perbandingan antara nilai NAPP dengan NAG $\mathrm{pH}$ (Net Acid Generation) yang penggolongannya terlihat pada Tabel 1.

\section{Pengambilan sampel}

Sampel yang digunakan dalam analisis berasal
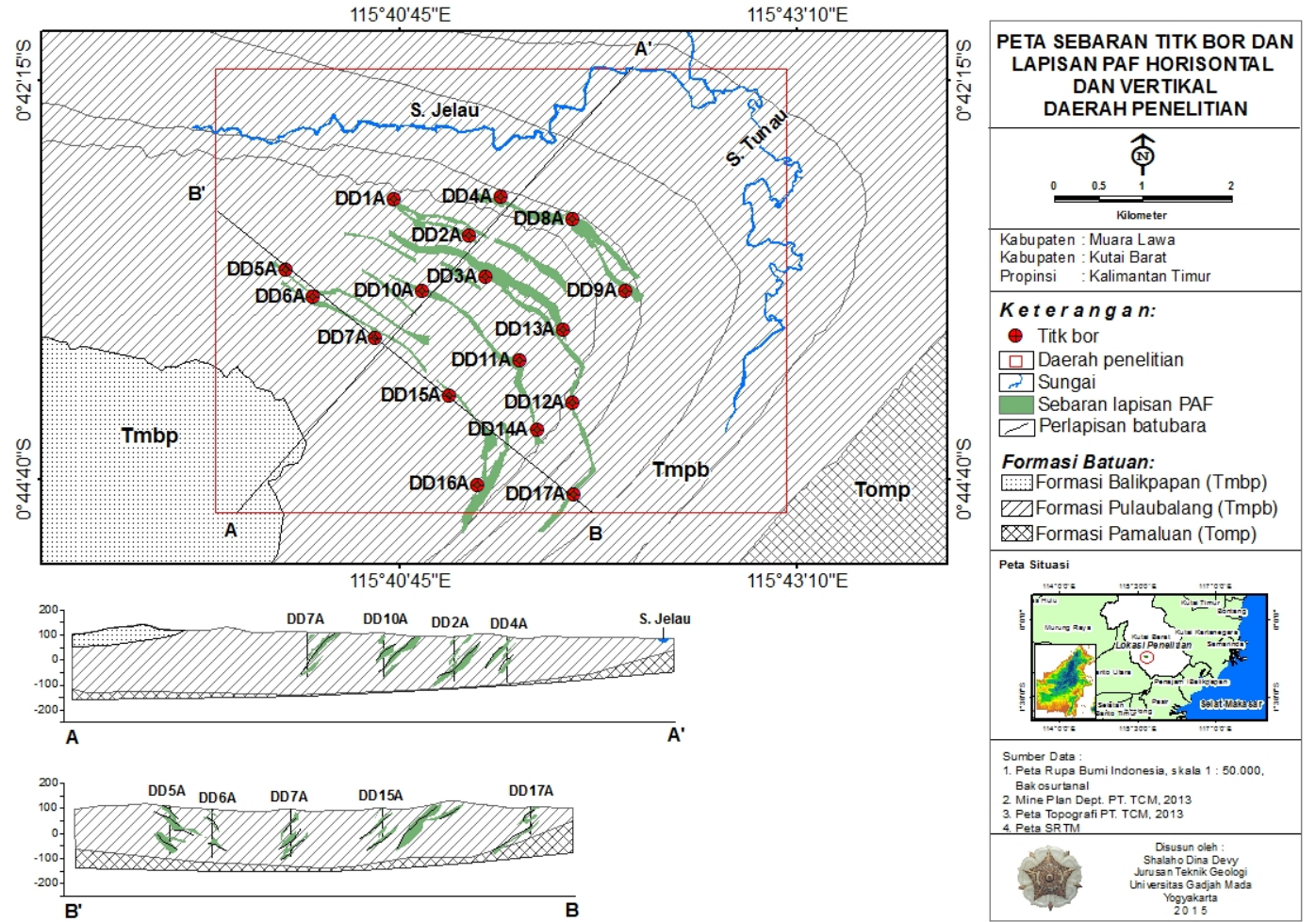

dari pemboran full coring pemboran AMD yang berupa batuan inti (core) dari 17 lubang bor. Sampel diambil rata-rata tiap interval kedalaman 0,5-1,6 m dari lubang bor yang pemilihannya dipengaruhi oleh jenis batuan dan kedalaman lubang pemboran. Jenis batuan yang diambil berupa batuan sedimen, antara lain batu lempung, batu lanau, dan batu pasir. Sampel-sampel tersebut digunakan sebagai database batuan untuk penghitungan nilai NAPP. Selanjutnya, nilai NAPP lapisan PAF/NAF digunakan sebagai data masukkan untuk pemodelan metode model blok dengan software surpac vision dan minescape.

\section{Analisis metode NAPP}

Menurut Marthen (2013) dan Ian dkk, (2007), bahwa analisis metode NAPP terdiri dari analisis \% TS, NAG pH, dan ANC. Parameter \% TS merupakan jumlah kandungan sulfur (organik/anorganik) dalam sampel batuan yang mengindikasikan jumlah asam sulfat yang terbentuk pada proses oksidasi dan reduksi dalam sampel. Prinsip kerja analisis TS yaitu dengan memijarkan sampel mencapai suhu \pm 1.250 ${ }^{\circ} \mathrm{C}$ ke dalam furnace type Lecco S-144DR. Oksidaoksida sulfur yang

Tabel 1. Kriteria batuan PAF dan NAF.

\begin{tabular}{cl}
\hline \multicolumn{1}{c}{ Parameter } & \multicolumn{1}{c}{ Kriteria } \\
\hline NAPP $\leq 0$ dan NAG $\mathrm{pH} \geq 4,5$ & NAF \\
NAPP $>0$ dan NAG $\mathrm{pH}<4,5$ & PAF \\
NAPP $>0$ dan NAG pH $>4,5$ & Uncertain \\
NAPP $\leq 0$ dan NAG pH $<4,5$ & Uncertain \\
\hline Sumber: Marthen (2013) dan Ian dkk., (2007)
\end{tabular}

Gambar 1. Peta sebaran titik bor dan lapisan PAF daerah penelitian. 
Tabel 2. Tabel karakteristik lapisan NAF dan PAF daerah penelitian.

\begin{tabular}{|c|c|c|c|c|c|}
\hline Titik bor & Dominasi batuan & $\begin{array}{c}\text { Total ketebalan } \\
(\mathrm{m})\end{array}$ & NAPP & NAG pH & Keterangan \\
\hline \multirow[t]{2}{*}{ DD1A } & Batu lanau & 4,6 & $-5,5$ & 6,5 & NAF \\
\hline & Batu lempung & 15,1 & 14,0 & 2,9 & PAF \\
\hline \multirow[t]{2}{*}{ DD2A } & Batu lanau & 23,4 & $-22,5$ & 6,8 & NAF \\
\hline & Batu lempung & 15,8 & 13,9 & 2,8 & PAF \\
\hline \multirow[t]{2}{*}{ DD3A } & Batu lanau lempungan & 13,8 & $-8,7$ & 6,7 & NAF \\
\hline & Batu lanau & 13,3 & 11,1 & 4,2 & PAF \\
\hline \multirow[t]{2}{*}{ DD4A } & Batu lanau pasiran & 14,1 & $-4,4$ & 6,7 & NAF \\
\hline & Batu lempung & 13,3 & 8,0 & 3,9 & PAF \\
\hline \multirow[t]{2}{*}{ DD5A } & Batu lanau & 33,5 & $-12,1$ & 6,7 & NAF \\
\hline & Batu lanau lempungan & 19,0 & 21,6 & 3,4 & PAF \\
\hline \multirow[t]{2}{*}{ DD6A } & Batu pasir lempungan & 18,1 & $-5,3$ & 6,6 & NAF \\
\hline & Batu lempung & 7,2 & 12,1 & 3,5 & PAF \\
\hline \multirow[t]{2}{*}{ DD7A } & Batu lanau & 33,1 & $-8,1$ & 6,7 & NAF \\
\hline & Batu lempung & 16,5 & 16,4 & 3,2 & PAF \\
\hline \multirow[t]{2}{*}{ DD8A } & Batu lanau lempungan & 43,9 & $-14,6$ & 6,6 & NAF \\
\hline & Batu lempung & 19,6 & 31,3 & 3,5 & PAF \\
\hline \multirow[t]{2}{*}{ DD9A } & Batu lempung lanauan & 30,6 & $-15,9$ & 7,3 & NAF \\
\hline & Batu lempung & 32,6 & 39,1 & 2,9 & PAF \\
\hline \multirow[t]{2}{*}{ DD10A } & Batu lempung & 24,0 & $-6,6$ & 7,3 & NAF \\
\hline & Batu lanau lempung & 15,0 & 10,3 & 3,6 & PAF \\
\hline \multirow[t]{2}{*}{ DD11A } & Batu lanau & 18,0 & $-12,9$ & 7,1 & NAF \\
\hline & Batu lempung & 27,0 & 32,3 & 3,1 & PAF \\
\hline \multirow[t]{2}{*}{ DD12A } & Batu pasir & 57,0 & $-22,0$ & 6,7 & NAF \\
\hline & Batu lempung & 2,0 & 46,1 & 2,9 & PAF \\
\hline \multirow[t]{2}{*}{ DD13A } & Batu lanau lempungan & 21,4 & $-4,3$ & 6,7 & NAF \\
\hline & Batu lempung & 20,4 & 22,3 & 3,5 & PAF \\
\hline \multirow[t]{2}{*}{ DD14A } & Batu lanau & 37,8 & $-6,0$ & 7,1 & NAF \\
\hline & Batu pasir & 7,7 & 37,8 & 3,4 & PAF \\
\hline \multirow[t]{2}{*}{ DD15A } & Batu lanau lempungan & 49,2 & $-7,7$ & 6,7 & NAF \\
\hline & Batu lempung & 12,2 & 8,1 & 3,2 & PAF \\
\hline \multirow[t]{2}{*}{ DD16A } & Batu lanau & 35,0 & $-12,0$ & 7,2 & NAF \\
\hline & Batu lempung & 10,6 & 16,9 & 3,1 & PAF \\
\hline \multirow[t]{2}{*}{ DD17A } & Batu lanau & 26,3 & $-9,1$ & 7,4 & NAF \\
\hline & Batu lempung & 15,7 & 20,8 & 3,7 & PAF \\
\hline
\end{tabular}

Sumber : Hasil analisis.

dihasilkan dari proses pemijaran ditangkap oleh sensor pendeteksi \% sulfur.

NAG merupakan analisis jumlah potensi keasaman yang terbentuk setelah terjadi oksidasi pirit dalam tanah/batuan tambang. Reaksi yang terjadi dalam NAG antara lain, reaksi keasaman dan penetralan dengan hasil akhir reaksi oksidasi adalah nilai NAG $\mathrm{pH}$ yang menunjukkan indikasi sifat keasaman atau kebasaan dari sampel batuan. Hasil analisis NAG pH di bawah 4,5 akan dilakukan tahap penitaran (titrasi) dengan larutan basa $\mathrm{NaOH} \mathrm{pH} \mathrm{4,5}$ dan dilanjutkan dengan $\mathrm{pH} 7$, jumlah larutan penitaran berbanding lurus dengan jumlah potensi asam dalam sampel.

ANC adalah metode penetapan jumlah mineral penetral (misalnya mineral karbonat, $\mathrm{CO}_{3}$ ) dalam batuan yang dapat bereaksi dengan mineral pengasam (misalnya mineral sulfida, $\mathrm{SO}_{4}$ ). Selain itu, ANC bermanfaat untuk menentukan kemampuan sampel dalam menetralkan asam yang terkandung dalam sampel itu sendiri. Jumlah nilai
ANC akan berpengaruh terhadap sifat alkalinitas sampel. Prinsip kerja penentuan ANC yaitu, mereaksikan kandungan mineral penetral $\left(\mathrm{CO}_{3}\right)$ dalam sampel dengan penambahan asam $(\mathrm{HCl})$ berlebih melalui penitrasian dengan basa $(\mathrm{NaOH})$ hingga $\mathrm{pH} 7$.

\section{HASIL DAN PEMBAHASAN}

\section{Hasil Analisis Metode NAPP}

Hasil analisis metode NAPP di laboratorium disajikan pada Tabel 2. Tabel ini terbagi menjadi lima kolom, yaitu titik lubang bor, dominasi batuan PAF/NAF dalam satu lubang bor, total ketebalan batuan tersebut, serta nilai NAPP dan NAG pH.

Tabel 2 mengindikasikan bahwa batu lanau mendominasi lapisan NAF dengan kisaran NAG pH 6,5-7,4 dan NAPP antara -4,3 hingga -22,5. Batu lanau mempunyai ketebalan terbesar pada sampel bor DD12A, yaitu $57 \mathrm{~m}$, dan lapisan tertipis pada sampel bor DD1A 4,6 meter. Ketebalan batuan 
didapat dari data pemboran vertikal perlapisan batuan, yaitu dengan cara mengakumulasi ketebalan batuan yang sama dalam satu lubang bor.

Sementara itu, pada Tabel 3, lapisan PAF didominasi oleh batu lempung yang dijumpai secara merata tiap sampel inti bor dengan kisaran NAG pH 2,8-4,2 dan NAPP antara 8,1 hingga 46,1. Batu lempung dari sampel lubang bor mempunyai ketebalan antara 1,95-32,6 m. Meskipun dijumpai lapisan yang sangat tebal (> 30 meter), namun penyebarannya hanya terfokus pada lokasi-lokasi yang mempunyai karaketeristik batuan tertentu, seperti sekitar lapisan batubara.

Secara keseluruhan lapisan NAF lebih mendominasi dari pada lapisan PAF dalam daerah penelitian. Selain itu, terdapat lapisan uncertain yang penyebaran terbatas pada lapisan aluvial.

\section{Pemodelan Sebaran Batuan PAF}

Pemodelan sebaran batuan NAF dan PAF dilakukan pada arah vertikal dan horisontal yang mendasarkan pada nilai NAPP pada PAF, yaitu lebih besar dari nol (Tabel 1). Sebaran vertikal bertujuan untuk mengetahui sebaran lapisan PAF dengan pembuatan penampang tegak lurus dengan jurus lapisan batuannya. Sementara itu, sebaran lateral atau horisontal meliputi sebaran lapisan PAF dari sebaran singkapan (cropline) yang mengikuti lipatan sinklin. Selain itu, penyebaran PAF juga mengikuti arah batuan yang cenderung mengikuti arah perlapisan kemiringan dari timur laut menuju ke barat daya.

Gambar 1 mendeskripsikan bahwa pola penyebaran lapisan PAF dibatasi oleh garis batas daerah penelitian. Terdapat dua warna dalam daerah penelitian, yaitu warna hitam dan putih. Warna hitam dalam bentuk poligon solid merupakan penyebaran dari lapisan PAF. Sementara itu, warna putih merupakan lapisan NAF dan lapisan tidak jelas (uncertain). Pada daerah penelitian, sebaran vertikal banyak didominasi batuan PAF yang dijumpai pada tanah penutup, lapisan antar batubara, dan lantai (floor) lapisan batubara. Sebaran horisontal lapisan PAF tersebar mengikuti jalur singkapan yang membentuk lipatan sinklin dan mengikuti singkapan dari batubara. Sebaran terluas dari lapisan PAF berada pada Formasi Pulaubalang yang mayoritas dijumpai pada batu lanau kemudian diikuti batu lempung dan batu pasir.

\section{KESIMPULAN}

Hasil pemodelan mengindikasikan, bahwa pada sayatan vertikal sebaran PAF banyak dijumpai pada tanah penutup, lapisan antar batubara, dan lantai (floor) lapisan batubara. Sebaran horisontal lapisan PAF tersebar mengikuti jalur lipatan sinklin dan mengikuti singkapan batubara. Sebaran terluas dari lapisan PAF berada pada Formasi Pulaubalang yang mayoritas dijumpai pada batu lempung kemudian diikuti batu lanau dan batu pasir.

Sementara itu, sebaran NAF mayoritas tersebar hampir merata (vertikal dan horisontal) pada batu lanau dan lapisan uncertain banyak dijumpai pada lapisan aluvial. Secara umum batuan daerah penambangan batubara tambang terbuka daerah Muara Lawa banyak didominasi oleh lapisan NAF, kemudian PAF, dan uncertain.

\section{UCAPAN TERIMAKASIH}

Penulis menyampaikan terimakasih kepada Managemen PT. Trubaindo Coal Mining tbk. (PT. TCM) dengan segenap staf dan karyawan daerah operasi penambangan di Kutai Barat, yang telah memberikan bantuan teknis, supervisi, dan nonteknis untuk operasional penelitian lapangan, sehingga penelitian ini selesai sesuai dengan target rencana yang diharapkan.

\section{DAFTAR PUSTAKA}

Ian, R., Taylor, J., Pape, S., Yardi, R., dan Bennett, J., 2007. Managing Acid and Metalliferous Drainage, Report for Departement of Industry Tourism and Resources, Australian Government, New South Wales, p. 95.

Jamal, A., Yadav, H.L., dan Pandey, S.S., 2015, Heavy Metal from Acid Mine Drainage in Coal Mines-A Case Study. European Journal of Advances in Engineering and Technology, 2(8):16-20.

Johnson, D.B., dan Hallberg, K.B., 2006. Acid Mine Drainage Remediation: A Review. Journal of Science of the Total Environment, 338:3-14.

Marthen, M., 2013. Identifikasi Potensi Pembentukan Air Asam Tambang, NAPP VS NTAPP, Buku Panduan, PT. Trubanindo Coal Mining, Kutai Barat.

Nugraha, C., Shimada, H., Sasaoka, T., Ichinose., M., dan Manage, M., 2009. Waste Rock Characteristics at Tropical Coal Mine Area: A Case Study of PT. Kaltim Prima Coal, Indonesia, International Journal of the JCRM, 5(2):77-82.

Quamruzzaman, C., Mondol, A.M., Ahmed, M.T., dan Ahmed, M.Z., 2014. A Proposal of Open Pit Coal Mine at the Northern Part of Barapukuria Coalfield, Dinajpur, Bangladesh, International Journal of Emerging Technology and Advanced Engineering, 4(3):482-488. 
Supriatna, S., Sukardi, dan Rustandi, 1995. Peta Geologi Bersistem, Lembar Samarinda, Kalimantan sekala 1:250.000, Pusat Penelitian dan Pengembangan Geologi Bandung.

Sigh, G., 2006. Impact of Coal Mining in Mine Water Quality, International Journal of Mine Water, Dhanbad, pp. 49-59.

Sand, W., Jozsa, P.G., Kovacs, S.M., Sasaren, N., dan Schippers, A., 2007. Long-term
Evaluation of Acid Rock Drainage Mitigation Measures in Large Lysimeters. Journal of Geochemical Exploration, 92(2-3):205-211.

Zulkarnain, A., dan Abdiyanto, M.D., 2012. Pemodelan Geokimia batuan Penutup Area Binungan Blok 9 PT. Berau Coal, Seminar Air Asam Tambang di Indonesia Ke-4, Bandung, pp. 23-30. 